\title{
FROM THE EDITORS: GARMISCH 80
}

Four years have passed since the Second World Congress for Soviet and East-European Studies, held in Garmisch-Partenkirchen from September 30 to October 4,1980 . When we committed ourselves to editing the papers and contributions by discussants of the philosophy panels of this congress we were not aware of all the difficulties ahead of us.

We should like to apologize to the authors and interested readers for the delay in publication. We are glad that the result of the authors' and our work will now appear in this and the subsequent issue of Studies in Soviet Thought.

We regret that the papers will not appear as a volume in the Sovietica series. In the end, insufficient size was the decisive reason for abandoning the original plan. The small size and long delay are due to various circumstances. The original plan called for a thematic book in English and not just for an edition of the congress papers. Most authors reworked their papers extensively for that purpose; in one case, a reply by an author was elicited and is now added. Several authors, it turned out, wanted to publish their papers elsewhere. Some contributions had to be deemed untranslatable. Twice, translations got lost in the mail and had to be redone. Also, both of us experienced adversities of a more private nature.

We hope that the papers in the form they now appear will still serve their purpose; and we gladly acknowledge the assistance, co-operation, and guidance we received from $T$. Blakeley, especially in the last phases of our endeavor.

PETER P. KIRSCHENMANN

ANDRIES SARLEMIJN

Studies in Soviet Thought 30 (1985), 193. 